\begin{tabular}{c}
\hline$J C E T, 1$ (1) Maret 2017 ISSN 2549-6379 (Print) ISSN 2549-6387 (Online) \\
JCEBT \\
ONournal of Civil Engineering, Building and Transportation) \\
Available online http://ojs.uma.ac.id/index.php/jcebt \\
\hline
\end{tabular}

\title{
Analisa Kenaikan Volume dan Kuat Tekan pada Campuran Beton Non Pasir dengan Penambahan Baking Powder
}

\section{Analysis of Volume and Strong Increase Press on Non-Sand Concrete Mixture with Addition of Baking Powder}

\author{
Afriansyah, Nurmaidah*, Amsuardiman \\ Program StudiTeknik Sipil, FakultasTeknik, Universitas Medan Area, Indonesia \\ *Coresponding Email: nurmaidah@gmail.com
}

Abstrak [Font: Cambria, size, 10, Bold]

Kebutuhan manusia akan bahan bangunan yang efisen, ekonomis dan mudah dalam pengerjaan, memicu penelitian dalam hal tersebut, salah satunya ialah beton, selai sebagai konstruksi bangunan beton juga berguana bagi konstruksi jalan raya yaitu rigid, dinding penahan, dan juga berguna untuk non struktural seperti dinding pemisah atau dinding isolasi dan dinding parit.Pada proses pembuatan bahan konstruksi banyak berbagai macam jenis dari semen, mulai dari portland tipe I, II dan III, semua jenis ini dimaksudkan memiliki fungsinya masing-masing, namun kembali lagi kebutuhan akan beton yang efisien, ekonomis dan workability lebih dicari. Untuk itu, banyak hal yang telah dilakukan dalam rangka mencari alternatif lain namun juga memikirkan efek lingkungan yang tidak berdampak negatif terhadap alam, salah satunya dengan cara mengurangi penggunaan pasir yang menghasilkan produk baru dari beton yang dikenal sebagai Beton Non pasir, dalam hal ini peneliti mencoba mengaplikasikan penggunaan campuran beton non pasir dengan penambahan baking powder dan faktor air semen yang lebih diperbesar yaitu 0,5 dengan maksud tidak mengurangi volume beton pada umumnya.Pada penelitian ini Baking Powder (Natrium Bikarbonat) dicampurkan dengan adonan beton dengan variasi $0 \%, 0,5 \%, 1 \%$, dan 1,5 \%, kemudian beton non pasir campuran baking powder akan diuji kuat tekan dan kenaikan volumenya.

Kata Kunci : Beton Nonpasir, Baking Powder, Kuat tekan, Volume

\begin{abstract}
Human needs for building materials that are efficient, economical and easy to work, trigger research in this regard, one of which is concrete, jam as a concrete building construction also berguana for highway construction that is rigid, retaining wall, and also useful for non structural like wall separator or wall of insulation and trench wall. In the process of making construction materials of many different types of cement, ranging from type I, II and III portland, all of these types are meant to have their respective functions, but again the need for efficient, economical concrete and more workability sought. For that, many things have been done in order to find other alternatives but also think about the environmental effects that do not have a negative impact on nature, one of them by reducing the use of sand that produces a new product of concrete known as Non-sand Concrete, in this case the researchers tried applying the use of mixture of non-sand concrete with the addition of baking powder and cement water factor that is more enlarged is 0.5 with the intention of not reducing the volume of concrete in general. In this study Baking Powder (Sodium Bicarbonate) mixed with a mixture of concrete with variations 0\%, 0 , $5 \%, 1 \%$, and $1.5 \%$, then non-sand concrete mixture of baking powder will be tested by compressive strength and volume increase.
\end{abstract}

Keywords: Non-Sanded Concrete, Baking Powder, Strong Press, Volume

How to Cite: Afriansyah, Nurmaidah, Amsuardiman. (2017). Analisa Kenaikan Volume dan Kuat Tekan pada Campuran Beton Non Pasir dengan Penambahan Baking Powder. JCEBT (Journal of Civil Engineering, Building and Transportation). 1 (1): 1-10 
PENDAHULUAN

Kemajuan dan perkembangan teknologi dalam bidang industri konstruksi semakin pesat memacu peningkatan pembangunan di segala sektor kehidupan. Kebutuhan fasilitas perumahan, perhubungan dan industri juga berdampak pada peningkatan kebutuhan bahan-bahan pendukungnya. Salah satu produk yang meningkat tajam adalah beton.

Beton merupakan salah satu bahan konstruksi yang banyak digunakan dalam pelaksanaan srtuktur bangunan modern. Seiring dengan pesatnya pembangunan di Indonesia, dimana aspek lingkungan harus diperhatikan dengan baik kelestariannya termasuk dalam hal penggunaan pasir yang juga merupakan sumber daya alam yang sebaiknya dibatasi penggunaannya. Teknologi beton yang modern saat ini memungkinkan penggunaan bahan-bahan yang berasal dari alam dapat dibatasi, dan disisi lain bahan adiktif dapat dimanfaatkan seoptimal mungkin untuk bahan dasar pembentukan beton.

Permasalahan utama diangkat pada penelitian ini adalah bagaimana pengaruh penambahan baking powder sebagai bahan tambahan pada campuran beton non pasir terhadap kenaikan volume beton dan kuat tekan beton itu sendiri.
Dalam proses penelitian yang dilakukan dapat menjadi acuan. Dan mengetahui urutan manakah yang terlebih dahulu digunakan pada saat pelaksaan di proyek dan di lapangan kerja. Maka untuk mendapatkan sasaran penelitian yang optimal penulis membatasai ruang lingkup tugas akhir ini sebagai berikut: a) Karakteristik yang diteliti adalah kenaikan volume dan kuat tekan beton; b) Beton yang diteliti ialah beton non pasir dengan campuran baking powder (natrium bikarbonat); c) Persentase penggunaan baking powder divariasikan dalam beberapa macam, yaitu $0 \%, 0,5 \%$, $1 \%, 1,5 \%$.

Untuk pengujian kuat tekan beton akan dibuat benda uji kubus sebanyak masing-masing 10 benda uji. Untuk baking powder sendiri kita dapatkan dari toko penyedia bahan kue. Beton non pasir dengan bahan tambahan baking powder bertujuan untuk mengetahui seberapa besar pengaruh penambahan baking powder terhadap kenaikan volume dan kuat tekan beton.

\section{METODE PENELITIAN}

Untuk lebih mendapatkan hasil peneleitian yang sesuai dengan yang diharapkan dan sekaligus dapat memperkecil kendala-kendala dalam pelaksanaanya. Maka diperlukan 
metodologi penelitian pengumpulan data (sample) dilakukan dengan melakukan survey dan penyedian bahan baku, pengujian bahan baku, rancangan campuran (Mix Design), pembuatan benda uji (kubus), pemeliharan, dan pengujian kuat tekan. Disamping itu untuk mendukung terlaksananya penulisan hasil penelitian ini diperlukan beberapa literatur baik dari buku-buku atau jurnal yang berkaitan dengan kasus ini.

Metode yang digunakan pada penelitian ini adalah kajian eksperimental yang dilakukan di Laboratorium Beton UPT. Pengujian Dan Pengendalian Mutu Dinas Binamarga Provsu. Objek dalam penelitian ini adalah beton non pasir dengan tambahan Natrium bikarbonat (Baking Powder) dengan variasi campuran $0 \%, 0,5 \%, 1 \%, 1,5 \%$. Sedangkan pengujian kuat tekan dan secara umum urutan tahap penelitian meliputi:

1. Penyediaan bahan-bahan penyusun beton,

2. Pemeriksaan bahan-bahan penyusun beton,

3. Perencanaan campuran beton (Mix design),

4. Pembuatan benda uji dan berat jenis beton segar,

5. Perawatan benda uji,

6. Pengukuran kenaikan volume beton,
7. Pengujian kuat tekan beton umur 28 hari.

8. Analisis kenaikan volume beton dilakukan setelah beton berumur 28 hari.

\section{HASIL DAN PEMBAHASAN}

Natrium bikarbonat adalah senyawa kimia dengan rumus $\mathrm{NaHCO}_{3}$. Dalam penyebutannya kerap disingkat menjadi bicnat. Senyawa ini termasuk kelompok garam dan telah digunakan sejak lama.

Senyawa ini disebut juga baking powder (powder kue), Sodium bikarbonat, natrium hidrogen karbonat, dan lain-lain. Senyawa ini merupakan kristal yang sering terdapat dalam bentuk serbuk. Natrium bikarbonat larut dalam air. Senyawa ini digunakan dalam roti atau kue karena bereaksi dengan bahan lain membentuk gaskarbon dioksida, yang menyebabkan roti "mengembang".

Senyawa ini disebut juga baking powder (powder kue), Sodium bikarbonat, natrium hydrogen karbonat, dan lain-lain. Senyawa ini merupakan kristal yang sering terdapat dalam bentuk serbuk. Natrium bikarbonat larut dalam air (Wikipedia, 2014). Powder kue diklasifikasikan sebagai garam asam, yang dibentuk dengan menggabungkan asam (karbonat) dandasar (natriumhidroksida), dan bereaksi dengan bahan kimia lain sebagai 
alkali ringan. Pada suhu di atas 300 derajat Fahrenheit (149 derajat Celcius), powder kue terurai menjadi natrium karbonat (zat lebih stabil), air, dan karbondioksida (Purwanto, 2012).

\section{Karakteristik Baking Powder} (Natrium Bikarbonat) adalah 1) Memiliki titik lebur yang tinggi; 2) Merupakan senyawa ionic dengan ikatan kuat; 3) Dalam bentuk leburan atau larutan dapat menghantarkan listrik; 4) Sifat larutannya dapat berupa asam, basa, atau netral. Sifat ini tergantung dari jenis asam/basa kuat pembentuknya (Pitriajuliani, 2012).

\section{Manfaat Baking Powder (Natrium} Bikarbonat)

Senyawa ini digunakan dalam roti atau kue karena bereaksi dengan bahan lain membentuk gas karbondioksida, yang menyebabkan roti "mengembang". Senyawa ini juga digunakan sebagai obat antasid (penyakit maag atau tukak lambung). Karena bersifat alkaloid (basa), senyawa ini juga digunakan sebagai obat penetral asam bagi penderita asidosistubulusrenalis (ATR) atau rhenal tubular acidosis (RTA). Selain itu, natrium bikarbonat juga dapat dimanfaatkan untuk menurunkan kadar asamurat (Wikipedia, 2014).

\section{Reaksi Kimia}

$\mathrm{NaHCO}_{3}$ umumnya diproduksi melalui proses Solvay, yang memerlukan reaksi natrium klorida, amonia, dan karbondioksida dalam air. $\mathrm{NaHCO}_{3}$ diproduksi sebanyak 100000 ton/tahun (2001). Powder kue juga diproduksi secara komesial dari powder abu (diperoleh melalui penambangan bijih trona, yang dilarutkan dalam air lalu direaksikan dengan karbondioksida. Lalu $\mathrm{NaHCO}_{3}$ mengendap sesuai persamaan berikut: $\mathrm{Na}_{2} \mathrm{CO}_{3}+\mathrm{CO}_{2}+\mathrm{H}_{2} \mathrm{O} \rightarrow 2 \mathrm{NaHCO}_{3}$ (Wikipedia, 2014).

$\mathrm{NaHCO} 3$ dapat diperoleh dengan reaksi antara karbondioksida dengan larutan natrium hidroksida. Reaksi awal menghasilkan natrium karbonat: $\mathrm{CO} 2+$ $2 \mathrm{NaOH} \rightarrow \mathrm{Na} 2 \mathrm{CO} 3+\mathrm{H} 2 \mathrm{O}$

Lebih lanjut penambahan karbon dioksida menghasilkan natriumbikarbonat, yang pada konsentrasi cukup tinggi akan mengendap larutan: $\mathrm{Na} 2 \mathrm{CO} 3+\mathrm{CO} 2+$ $\mathrm{H} 2 \mathrm{O} \rightarrow 2 \mathrm{NaHCO} 3$ (Purwanto, 2012).

Beton Beton merupakan ikatan dari material-material pembentuk beton, yaitu terdiri dari campuran agregat (kasar dan halus), semen, air, dan ditambah dengan campuran tertentu apabila dianggap perlu. Bahan air dan semen disatukan akan membentuk pasta semen yang berfungsi sebagai bahan pengikat, sedangkan 
agregat halus dan agregat kasar sebagai pengisi. (Paul Nugraha \& Antoni, 2007)

Kelebihan beton adalah mampu menahan gaya tekan dengan baik, serta mempunyai sifat tahan terhadap korosi dan pembusukan oleh kondisi lingkungan; Beton segar dapat dengan mudah dicetak sesuai dengan keinginan. Cetakan dapat pula dipakai berulang kali sehingga lebih ekonomis; Beton segar dapat disemprotkan pada permukaan beton lama yang retak maupun dapat diisikan kedalam retakan beton dalam proses perbaikan; Beton segar dapat dipompakan sehingga memungkinkan untuk dituang pada tempat-tempat yang posisinya sulit; Beton tahan aus dan tahan bakar, sehingga perawatannya lebih murah.

Kekurangan beton adalah dianggap tidak mampu menahan gaya tarik, sehingga mudah retak. Oleh karena itu perlu di beri baja tulangan sebagai penahan gaya Tarik; Beton keras menyusut dan mengembang bila terjadi perubahan suhu, sehingga perlu dibuat dilatasi (expansion joint) untuk mencegah terjadinya retakan -retakan akibat terjadinya perubahan suhu; Untuk mendapatkan beton kedap air secara sempurna, harus dilakukan dengan pengerjaan yang teliti; Beton bersifat getas (tidak daktail) sehingga harus dihitung dan diteliti secara seksama agar setelah dikompositkan dengan baja tulangan menjadi bersifat daktail, terutama pada struktur tahan gempa.

Tabel 1. Unsur-unsur beton

\begin{tabular}{ll}
\hline Agregat (kasar+halus) & $60 \%-80 \%$ \\
\hline Semen & $7 \%-15 \%$ \\
\hline Air & $14 \%-21 \%$ \\
\hline Udara & $1 \%-8 \%$ \\
\hline
\end{tabular}

(Sumber: Teknologi Beton, 2007)

Semen diartikan sebagai bahan perekat yang memiliki sifat mampu mengikat bahan - bahan padat menjadi satu kesatuan yang kompak dan kuat. (Bonardo Pangaribuan, Holcim). Semen merupakan hasil industri yang sangat kompleks, dengan campuran serta susunan yang berbeda-beda. Semen dapat dibedakan menjadi dua kelompok, yaitu: 1). Semen non-hidrolik, dan 2). Semen Hidrolik.

Agregat adalah sekumpulan butirbutir batu pecah, kerikil, pasir, atau mineral lainnya baik berupa hasil alam maupun buatan (SNI No: 1737-1989-F). Agregat adalah material granular, misalnya pasir, kerikil, batu pecah yang dipakai bersama-sama dengan suatu media pengikat untuk membentuk suatu beton semen hidraulik atau adukan.

Air yang digunakan adalah air bersih yang bisa diminum, air diperlukan dalam pembuatan beton untuk memicu proses kimiawi semen, membasahi agregat dan memberikan kemudahan dalam 
pengerjaan beton. Semen tidak bisa dimaksudkan untuk mendapatkan hasil menjadi pasta tanpa air. Air harus selalu peningkatan volume beton dengan ada didalam beton cair, tidak saja untuk menggunakan bahan tambah Natrium hidrasi semen, tetapi juga untuk mengubah Bikarbonat. Hasil Pengujian kenaikan menjadi suatu pasta sehingga betonnya volume kubus beton dapat dilihat pada lecak (workable). tabel berikut :

Pengujian Kenaikan volume beton dilakukan setelah 24 jam pengecoran

Tabel 2. Hasil Pengujian Kenaikan Volume Persentase Campuran o\%

\begin{tabular}{llllll}
\hline $\begin{array}{l}\text { Variasi } \\
\text { Penambahan }\end{array}$ & $\begin{array}{l}\text { No. } \\
\text { Benda Uji }\end{array}$ & $\begin{array}{l}\text { Berat } \\
(\text { gram })\end{array}$ & $\begin{array}{l}\text { Tinggi awal } \\
(\mathrm{cm})\end{array}$ & $\begin{array}{l}\text { Tinggi } \\
\text { Akhir }(\mathrm{cm})\end{array}$ & $\begin{array}{l}\text { Selisih } \\
(\mathrm{cm})\end{array}$ \\
\hline o \% & 1 & 5661 & 11,5 & 11,5 & o \\
\hline o \% & 2 & 5598 & 11,5 & 11,5 & o \\
\hline o \% & 3 & 5704 & 11,5 & 11,5 & o \\
\hline o \% & 4 & 5689 & 11,5 & 11,5 & o \\
\hline o \% & 5 & 5700 & 11,5 & 11,5 & o \\
\hline Rata -rata & & 5670,4 & 11,5 & 11,5 & o \\
\hline
\end{tabular}

\begin{tabular}{llllll}
\hline \multicolumn{2}{c}{ Tabel 3. Hasil Pengujian Kenaikan Volume Persentase Campuran o,5\% } \\
\hline $\begin{array}{l}\text { Variasi } \\
\text { Penambahan }\end{array}$ & $\begin{array}{l}\text { No. } \\
\text { Benda Uji }\end{array}$ & $\begin{array}{l}\text { Berat } \\
(\mathrm{gram})\end{array}$ & $\begin{array}{l}\text { Tinggi awal } \\
(\mathrm{cm})\end{array}$ & $\begin{array}{l}\text { Tinggi } \\
\text { Akhir }(\mathrm{cm})\end{array}$ & $\begin{array}{l}\text { Selisih } \\
(\mathrm{cm})\end{array}$ \\
\hline $0,5 \%$ & $\mathbf{1}$ & 5742 & 11,5 & 11,5 & 0 \\
\hline $0,5 \%$ & 2 & 5698 & 11,5 & 11,5 & 0 \\
\hline $0,5 \%$ & 3 & 5700 & 11,5 & 11,5 & 0 \\
\hline $0,5 \%$ & 4 & 5650 & 11,5 & 11,5 & 0 \\
\hline $0,5 \%$ & 5 & 5452 & 11,5 & 11,5 & 0 \\
\hline Rata -rata & & 5648,4 & 11,5 & 11,5 & 0
\end{tabular}

Tabel 4. Hasil Pengujian Kenaikan Volume Persentase Campuran 1\%

\begin{tabular}{|c|c|c|c|c|c|c|}
\hline $\begin{array}{l}\text { Variasi } \\
\text { Penambahan }\end{array}$ & $\begin{array}{l}\text { No. } \\
\text { Benda Uji }\end{array}$ & $\begin{array}{l}\text { Berat } \\
\text { (gram) }\end{array}$ & & $\begin{array}{l}\text { Tinggi awal } \\
(\mathrm{cm})\end{array}$ & $\begin{array}{l}\text { Tinggi Akhir } \\
(\mathrm{cm})\end{array}$ & $\begin{array}{l}\text { Selisih } \\
(\mathrm{cm})\end{array}$ \\
\hline $1 \%$ & 1 & 5604 & & 11,5 & 11,5 & 0 \\
\hline $1 \%$ & 2 & 5709 & & 11,5 & 11,5 & $\mathrm{O}$ \\
\hline $1 \%$ & 3 & 5689 & & 11,5 & 11,5 & o \\
\hline $1 \%$ & 4 & 5599 & & 11,5 & 11,5 & o \\
\hline $1 \%$ & 5 & 5712 & & 11,5 & 11,5 & o \\
\hline Rata -rata & & 5662,6 & & 11,5 & 11,5 & $\mathrm{O}$ \\
\hline \multicolumn{7}{|c|}{ Tabel 5. Hasil Pengujian Kenaikan Volume Persentase Campuran 1,5\% } \\
\hline $\begin{array}{l}\text { Variasi } \\
\text { Penambahan }\end{array}$ & $\begin{array}{l}\text { No } \\
\text { Ber }\end{array}$ & Uji & $\begin{array}{l}\begin{array}{l}\text { Berat } \\
\text { (gram) }\end{array} \\
\end{array}$ & $\begin{array}{l}\text { Tinggi awal } \\
(\mathrm{cm})\end{array}$ & $\begin{array}{l}\text { Tinggi } \\
\text { Akhir }(\mathrm{cm})\end{array}$ & $\begin{array}{l}\text { Selisih } \\
(\mathrm{cm})\end{array}$ \\
\hline $1,5 \%$ & 1 & & 5714 & 11,5 & 11,5 & $\mathrm{O}$ \\
\hline $1,5 \%$ & 2 & & 5689 & 11,5 & 11,5 & o \\
\hline $1,5 \%$ & 3 & & 5709 & 11,5 & 11,5 & o \\
\hline $1,5 \%$ & 4 & & 5659 & 11,5 & 11,5 & 0 \\
\hline $1,5 \%$ & 5 & & 5622 & 11,5 & 11,5 & 0 \\
\hline Rata -rata & & & 5678,6 & 11,5 & 11,5 & $\mathrm{O}$ \\
\hline
\end{tabular}

Sumber: Hasil Penelitian lab. Beton UPTD. Dinas Bina Marga Provsu 2016 


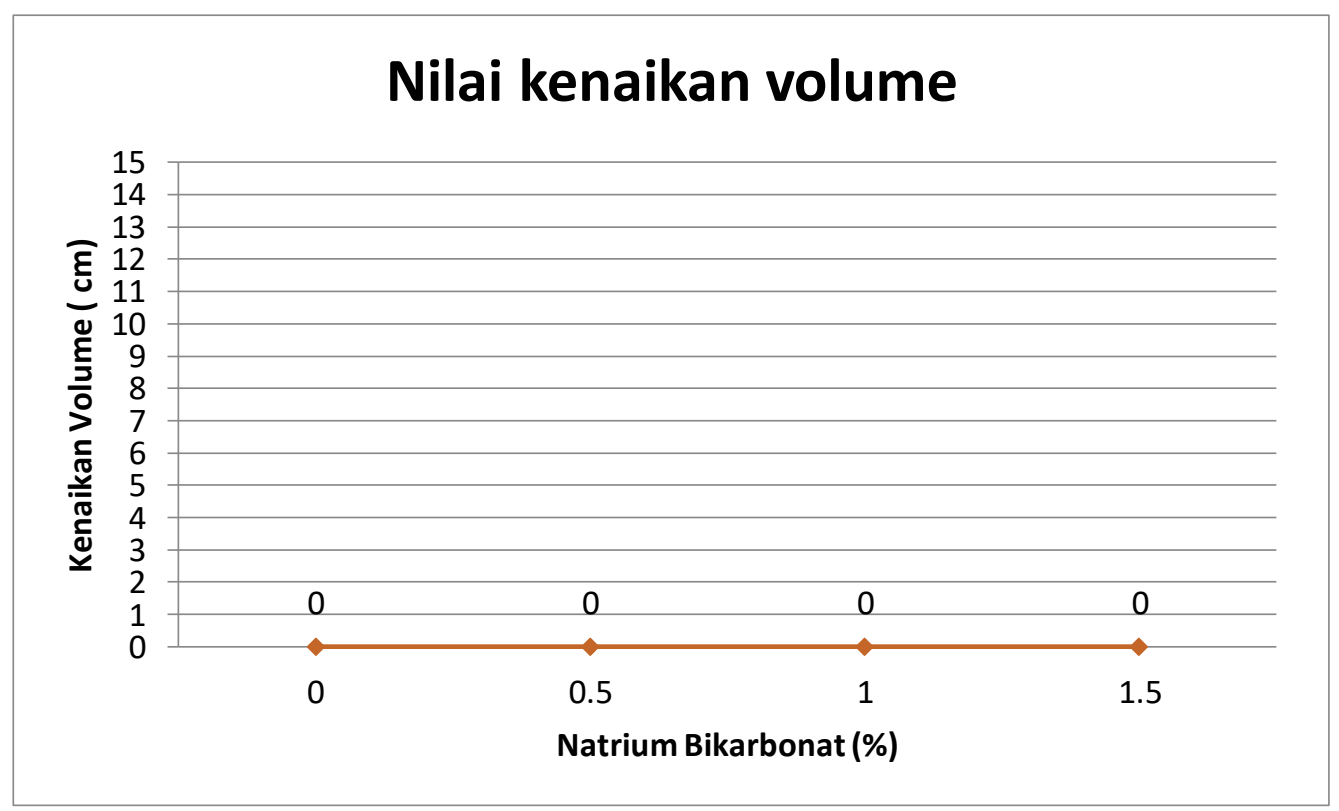

Gambar 1. Grafik Hubungan kenaikan volume terhadap penambahan natrium Bikarbonat Dari hasil pengujian kenaikan volume

\section{Pengujian Kuat Tekan Kubus Beton}

kubus beton tidak terjadi perubahan

Pengujian kuat tekan beton dilakukan volume apapun pada beton sejalan pada umur 28 hari dimaksudkan untuk penambahan baking powder (natrium mendapatkan hasil peningkatan kekuatan bikarbonat) dengan variasi $0,5 \%, 1 \%$, dan $1,5 \%$.

Dikarenakan persentase penambahan baking powder terlalu kecil. tekan beton dengan menggunakan bahan tambah Natrium

Adapun penurunan kuat tekan beton pada

Bikarbonat

dan hasilnya penelitian ini terjadi karena pengaruh Natrium Bikarbonat (Baking Powder). dibandingkan dengan beton normal. Berikut hasil pengujian kuat tekan kubus beton dapat dilihat pada:

Tabel 6. Hasil Kuat Tekan Beton Persentase Campuran o\%

\begin{tabular}{|c|c|c|c|c|c|}
\hline $\begin{array}{l}\text { Variasi } \\
\text { penambahan }\end{array}$ & $\begin{array}{l}\text { No. } \\
\text { Benda Uji }\end{array}$ & $\begin{array}{l}\text { Berat } \\
(\mathrm{kg})\end{array}$ & $\begin{array}{l}\text { Berat } \\
\text { Rata-rata }(\mathrm{kg})\end{array}$ & $\begin{array}{l}\text { Hasil Kuat } \\
\text { Tekan kg/m³) }\end{array}$ & $\begin{array}{l}\text { Kuat Tekan } \\
\text { Rata-rata }\end{array}$ \\
\hline o \% & 1 & 7595 & & 174,54 & \\
\hline o \% & 2 & 7605 & & 179,05 & \\
\hline o \% & 3 & 7580 & & 172,60 & \\
\hline o\% & 4 & 7593 & & 169,87 & \\
\hline o \% & 5 & 7610 & 7594,5 & 175,02 & 174,81 \\
\hline o \% & 6 & 7605 & & 176,50 & \\
\hline o \% & 7 & 7590 & & 174,32 & \\
\hline o \% & 8 & 7622 & & 169,78 & \\
\hline o \% & 9 & 7570 & & 177,60 & \\
\hline o\% & 10 & 7575 & & 178,89 & \\
\hline
\end{tabular}


Afriansyah, Nurmaidah, Amsuardiman. Analisa Kenaikan Volume dan Kuat Tekan pada Campuran Beton

Tabel 7. Hasil Kuat Tekan Beton Persentase Campuran o, $5 \%$

\begin{tabular}{llllll}
\hline Variasi penambahan & No. Benda Uji & Berat $(\mathrm{kg})$ & $\begin{array}{l}\text { Berat } \\
\text { Rata -rata }(\mathrm{kg})\end{array}$ & $\begin{array}{l}\text { Hasil } \\
\text { Tekan }\left(\mathrm{kg} / \mathrm{m}^{3}\right)\end{array}$ & $\begin{array}{l}\text { Kuat } \\
\text { Rata-rata }\end{array}$ \\
\hline $0,5 \%$ & 1 & 7635 & & 159,20 & \\
\hline $0,5 \%$ & 2 & 7598 & & 161,05 & \\
\hline $0,5 \%$ & 3 & 7550 & & 160,60 & \\
\hline $0,5 \%$ & 4 & 7615 & & 161,70 & 159,76 \\
\hline $0,5 \%$ & 5 & 7631 & 7594,5 & 160,09 & 161,00 \\
\hline $0,5 \%$ & 6 & 7620 & & 160,54 & \\
\hline $0,5 \%$ & 7 & 7601 & & 157,30 & \\
\hline $0,5 \%$ & 8 & 7588 & & 157,40 & \\
\hline $0,5 \%$ & 9 & 7635 & 158,80 & \\
\hline $0,5 \%$ & 10 & 7610 & & & \\
\hline
\end{tabular}

\begin{tabular}{llllll}
\hline \multicolumn{5}{c}{ Tabel 8. Hasil Kuat Tekan Beton Persentase Campuran 1 } \\
\hline $\begin{array}{l}\text { Variasi } \\
\text { penambahan }\end{array}$ & $\begin{array}{l}\text { No. } \\
\text { Benda Uji }\end{array}$ & $\begin{array}{l}\text { Berat } \\
(\mathrm{kg})\end{array}$ & $\begin{array}{l}\text { Berat } \\
\text { Rata-rata }(\mathrm{kg})\end{array}$ & $\begin{array}{l}\text { Hasil } \\
\text { Tekan }\left(\mathrm{kg} / \mathrm{m}^{3}\right)\end{array}$ & $\begin{array}{l}\text { Kuat } \\
\text { Rata-rata }\end{array}$ \\
\hline $1 \%$ & 1 & 7650 & & 150,20 & \\
\hline $1 \%$ & 2 & 7587 & & 148,05 & \\
\hline $1 \%$ & 3 & 7640 & & 149,60 & \\
\hline $1 \%$ & 4 & 7530 & & 146,70 & 146,17 \\
\hline $1 \%$ & 5 & 7489 & 7601,3 & 143,10 & \\
\hline $1 \%$ & 6 & 7630 & & 144,54 & \\
\hline $1 \%$ & 7 & 7545 & & 142,30 & \\
\hline $1 \%$ & 8 & 7750 & & 149,40 & \\
\hline $1 \%$ & 9 & 7587 & & & \\
\hline $1 \%$ & 10 & 7605 & & & \\
\hline
\end{tabular}

\begin{tabular}{llllll}
\hline \multicolumn{6}{l}{ Tabel 9. Hasil Kuat Tekan Beton Persentase Campuran 1,5\% } \\
\hline $\begin{array}{l}\text { Variasi } \\
\text { penambahan }\end{array}$ & $\begin{array}{l}\text { No. } \\
\text { Benda Uji }\end{array}$ & $\begin{array}{l}\text { Berat } \\
(\mathrm{kg})\end{array}$ & $\begin{array}{l}\text { Berat } \\
\text { Rata-rata }(\mathrm{kg})\end{array}$ & $\begin{array}{l}\text { Hasil } \\
\text { Tekan }\left(\mathrm{kg} / \mathrm{m}^{3}\right)\end{array}$ & $\begin{array}{l}\text { Kuat } \\
\text { Rata-rata }\end{array}$ \\
\hline $1,5 \%$ & 1 & 7704 & & 130,20 & \\
\hline $1,5 \%$ & 2 & 7532 & 131,05 & \\
\hline $1,5 \%$ & 3 & 7623 & 135,60 & \\
\hline $1,5 \%$ & 4 & 7587 & 139,70 & \\
\hline $1,5 \%$ & 5 & 7497 & 7585 & 135,09 & \\
\hline $1,5 \%$ & 6 & 7589 & 131,00 & \\
\hline $1,5 \%$ & 7 & 7615 & 138,54 & \\
\hline $1,5 \%$ & 8 & 7643 & 138,30 & \\
\hline $1,5 \%$ & 9 & 7490 & 137,40 & \\
\hline $1,5 \%$ & 10 & 7570 & 139,80 & \\
\hline
\end{tabular}

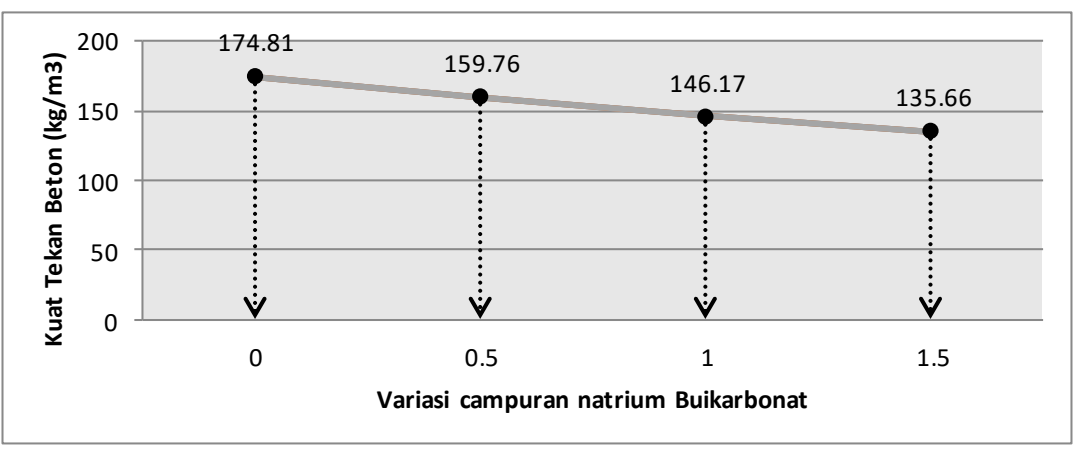

Gambar 2.Grafik hubungan kuat tekan kubus terhadap variasi penambahan Natrium Bikarbonat 
Dari hasil pengujian kuat tekan beton kubus pada umur 28 hari terjadi penurunan kuat tekan beton yang signifikan sejalan penambahan Natrium Bikarbonat dengan variasi 0,5 \%, $1 \%, 1,5$ $\%$, dimana penurunan terjadi sebesar 8,6 $\%, \quad 16,38 \%, \quad 22,39 \%$ terhadap beton normal.

\section{SIMPULAN}

Penurunan kekuatan tekan beton akibat dari pengaruh pelepasan gas karbon dioksida yang terlalu tinggi, dan juga dikarenakan natrium bikarbonat bersifat asam korosif bagi beton. Reaksi ikatan kimia antara Semen + Air + Natrium Bikarbonat bersifat menggumpal, penggumpalan pada saat hidrasi timbul karena semen menyerap uap air dan $\mathrm{CO} 2$ dalam jumlah yang cukup banyak sehingga terjadi penggumpalan. Semen yang menggumpal kualitasnya akan menurun karena bertambahnya Loss On Ignition (LOI) dan menurunnya spesifikgravity sehingga kekuatan semen menurun, waktu pengikatan dan pengerasan semakin lama, dan terjadinya false set. Dari hasil pengujian kenaikan volume tidak terjadi perubahan volume apapun sejalan penambahan variasi persentase bubuk Natrium Bikarbonat atau yang kita kenal sebagai bubuk Baking powder dikarenakan persentase penambahan yang terlalu kecil. Sejalan penambahan bubuk baking powder pada sampel yang masingmasing 10 sampel tiap variasi dengan persentase $0,5 \%, 1 \%, 1,5 \%$, dimana kuat tekan tertinggi terletak pada campuran baking powder dengan kadar 0,5\% yaitu $159,76 \mathrm{~kg} / \mathrm{cm}^{3}$, dan bobot isi beton tertinggi terletak pada campuran baking powder dengan kadar 1,5\% yaitu 2099,04 $\mathrm{kg} / \mathrm{m}^{3}$ dan terendah pada kadar $0,5 \%$ yaitu $2094,87 \mathrm{~kg} / \mathrm{m}^{3}$.

\section{DAFTAR PUSTAKA}

ACI Committee 201, (1994), Guide to Durable Concrete (ACI Manual of Concrete Practise) Part I, American Concrete Institute, Detroit Michigan.

ACI Committee 211, (1993), "Guide for Selecting Proportions for Normal Heavyweight, and Mass Concrete (ACI 211.1-91), American Concrete Institute, Detroit Michigan.

Departemen PU, (1989), "Spesifikasi Bahan Bangunan Bagian A(SK SNI S-04-1989-F)", Yayasan LPMB, Bandung.

Indonesia, W. b. (2014, Maret 11). Natrium Bikarbonat. Retrieved Oktober 1, 2013, from Wikipedia bahasa Indonesia

Mindess.S dan Young. J. Francis, (1981). " Concrete" Prentice-Hall,.

Murdock L.J, Brook K.M, (1986), "Bahan dan Praktek Beton", Erlangga,

Mulyono, Try. (2003). Teknologi Beton. Yogyakarta: Penerbit Andi.

Nugraha, Paul. (2007). Teknologi Beton. Yogyakarta: Penerbit Andi.

Pitriajuliani. (2012, Desember 9). WordPress.com. Retrieved Maret 11, 2014,

Purwanto, S. A. (2012, Januari 24). Industri Powder Kue. Retrieved Maret 11, 2014

Puja, A dan Rachmat, P. (2010), "Pengendalian Mutu Beton sesuai SNI, ACI dan ASTM", ITS Press Surabaya. 